Kolata, is from my work. A brief report can be found in Kalahari Huntergatherers ${ }^{2}$. A full account, including data, methods and analyses (including a comparison with the Hutterites and a consideration of the implications of the Frisch hypothesis) will be found in my forthcoming book ${ }^{3}$.

The figure of $15.5 \mathrm{yr}$ for the mean age at menarche for !Kung girls (quoted by Kolata from a telephone interview) has been superceded by a mean of $16.5 \mathrm{yr}$, calculated from a larger group of observations. !Kung women may be anovulatory during some substantial portion of their birth intervals (mean length 35.4 months for all intervals observed during an eleven year period, $n=102$ ) but they are not amenorrheic for this whole period.

It is tempting but premature to generalise from the !Kung to hunter-gatherers in general and hence to prehistoric populations. The low fertility of the !Kung suggests a stimulating hypothesis on the nature of population dynamics in such groups, as discussed by May, but exploring that hypothesis will require considerable additional research on other groups.

Department of Sociology,

University of Toronto,

Toronto, Ontario, Canada

1. May, R. M. Nature 272, 491-495 (1978).

2. Howell, N. in Kalahari Hunter-gatherers (eds Lee, R. \& DeVore. I.) (Harvard University Press. Cambridge, 1976)

3. Howell, N. Demography of the Dobe !Kung (Academic, New York, in the press).

\section{The neural representation of visual space}

DRASDO $^{1}$, and Lennie ${ }^{2}$, attribute Rolls and Cowey ${ }^{3}$ with the demonstration that monkey cortical magnification factor, $M$, varies as the square root of the ganglion cell density which deals with the corresponding region of visual field. Lennie's discussion is based on the development of this relationship for monkey and man. In fact, Rolls and Cowey report $M$ to be proportional to ganglion cell density $\mathrm{deg}^{2}$, not to its square root, both within and outside the foveal area.

Such proportionality between retinal ganglion cell density $\operatorname{deg}^{2}$ and $M$ has also been described at several stations of the visual pathways in a variety of species ${ }^{4-7}$. It has been a long-standing puzzle as to why a linear measurement, $M$, should be proportional to a retinal cell density.

The outcome of Drasdo's data manipulations, that human cortical magnification factor is proportional to the square root of the ganglion cells serving the corresponding region of visual field (that is, of his receptive field density, $D_{\mathrm{r}}$ ), is thus not at all in agreement with the findings of Rolls and Cowey. If valid, it is the first instance of such a relationship and implies that the human visual cortex is organised in a quite different fashion from that of saimiri or macaque, or indeed from that of cat and rabbit.

However, the data on which Drasdo's conclusions are based are not sound enough to warrant a belief that the human cortex deviates so markedly from the organisation apparently common to a variety of species. The ganglion cell distributions which he pooled ${ }^{8-10}$ were all obtained by the unreliable technique of counting on radial sections not subject to an Abercrombie correction ${ }^{11}$. Also, there is no evidence of common criteria for ganglion cells, shrinkages were not measured and the distributions plotted separately can support quite different interpretations from those of Drasdo. It perhaps suffices to point out that the results of Van Buren indicate densities of from one to more than two orders of magnitude greater than those of Oppel at the equivalent eccentricity. Correction for optical magnification is a nicety in such circumstances.

Of course, it would be pleasing if Drasdo's conclusions were valid, because the recent demonstration ${ }^{12}$ of proportionality between human acuity and cortical magnification factor could then relate acuity directly to ganglion cell angular separation. In my opinion the evidence is against such a relationship in $\operatorname{man}^{13}$ or cat ${ }^{14}$ but, as Lennie points out, knowledge of the distribution of the specific ganglion cell class involved in resolution tasks may elucidate the matter. Note added in proof: Lennie's editorial remains explicitly misleading. This might have been avoided had Drasdo emphasised that he claimed differences between man and monkey which necessitated analysis in terms of $\sqrt{D_{\mathrm{r}}}$, rather than $D_{r}$, and $M$. However, I remain unconvinced; the densities of Van Buren and Oppel differ more than 100-fold at the same eccentricity in the original data quite independent of errors introduced by replotting; similar large discrepancies occur throughout their data and preclude pooling.

\section{Department of Physiology, John Curtin School of Medical Research, Australian National University, PO Box 334, Canberra City, ACT 2601 Australia}

\footnotetext{
. Drasdo, N. Nature 266, 554-556 (1977).

2. Lennie, P. Nature 266, $496(1977)$

3. Rolls, E. T. \& Cowey, A. Expl Brain Res. 10, 298-310 (1970).

4. Jacobsen, M. Q. J. exp. Physiol. 47, 170-178 (1962).

5. Sanderson, K. J. exp. Brain Res. 13, 159-177 (1971).

6. Hughes, A. Documenta ophth. 30, 33-159 (1971).

7. Webb, S. V. \& Kaas, J. H. Vision Res. 16, 1247-1254 (1976).

8. Vilter, V. C. r. Séanc. Soc. Biol. 148, 220-223 (1954).

9. Van Buren, J. M. The Retinal Ganglion Cell Layer (Thomas, Springfield, 1963).

10. Oppel, O. Albrecht v. Graefes Arch. Ophthal. 172, 1-22
} (1967).
11. Abercrombie, M. Anat. Rec. 94, 239-247 (1946).

12. Cowey, A. \& Rolls, E. T. Expl Brain Res. 21, 447-454 (1974).

13. Hughes, A. Handbook of Sensory Physiology. Vol. 7/5 A (Springer, Berlin, 1977).

14. Tusa, R. J., Paimer, L. A. \& Rosenquist, A. C. J. comp. Neurol. 177, 213-235 (1978).

DRASDO REPLIES—Some responsibility is accepted for the scepticism evinced by Hughes, whose comments on my letter ${ }^{1}$ can be traced to two irregularities on points of detail ${ }^{2}$. However, this scepticism should not extend to the material contents of the letter which can be shown to be unaffected. As Hughes indicates, the root sign in the first paragraph is regrettably misplaced. This relationship observed in animals was stated correctly in the following paragraph.

Apparent differences between the vision of man and other animals should not cause surprise. Even in other primates, predation, falls and fighting contribute largely to mortality ${ }^{3}$; survival may be related to peripheral and tectal vision, and correspondingly the human extra foveal retina has fewer presumed transient and feature-detecting ganglion cells ${ }^{4}$.

The ganglion cell density distributions differed systematically; literally, to pool them would have been reprehensible. Instead, a mean line was taken between the two sets for each meridian (see Fig. 1, ref. 1). Shrinkage corrections for data of Oppel and Van Buren were based on fovea-papilla distance, which further reduces disparities by correcting for eye size. Paradoxically, Oppel's ${ }^{5}$ original estimated total count fell short of Van Buren's ${ }^{6}$ by only $40 \%$, despite the extreme discrepancies referred to by Hughes.

I am indebted to Hughes, who inadvertently brought to my attention an incorrectly plotted point which, when corrected $^{2}$, reduced the discrepancy between cells and receptive fields in the area affected by excavation to $3 \%$, giving further support to the calculation (see legend to Fig. 1, ref. 1).

The possibility of an overcount of ganglion cells is well known $n^{6.7}$, but as with the other data used these were the best estimates available and all show an impressive alignment with the empirical equation which remains attractive for its simplicity and usefulness in the present state of knowledge.

\section{N. DRASDO \\ Department of Ophthalmic Optics, University of Aston in Birmingham, Birmingham, UK}

\footnotetext{
1. Drasdo, N. Nature 266, 554-556 (1977). 2. Corrigendum Nature 272, 840 (1977).

3. Schultze, A. H. The Life of the Primates, 130, 193-199 (Wiedenfield and Nicholson, London, 1969).

4. Dubin, M. W. in The Eye, Vol. 6, eds Davson, H. \& Graham, L. T. J. 249-254 (Academic, London, 1974),

5. Oppel, O. Albrecht v. Graefes Arch. Ophthal. 172, 1-22 (1967).

6. Van Buren, J. M. The Retinal Ganglion Cell Layer, 128130 (Thomas, Springfield, 1963).

7. Rolls, E. T. \& Cowey, A. Expl Brain Res. 10, 298-310
} (1970). 